
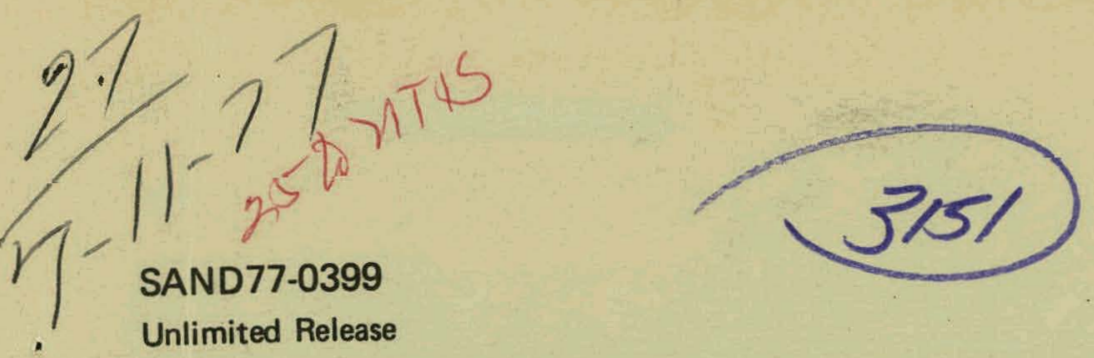

\title{
Characteristics of Holograms Recorded on AGFA 10E75 Plates and Processed in D6X Developer
}

Gary S. Phipps, Clarence E. Robertson

Prepared by Sandia Laboratories. Albuquerque New Mexico 87115

and Livermore, California 94550 for the United States Energy Research

and Development Administration under Contract AT (29-1).789

Printed June 1977

\section{Sandia Laboratories}




\section{DISCLAIMER}

This report was prepared as an account of work sponsored by an agency of the United States Government. Neither the United States Government nor any agency Thereof, nor any of their employees, makes any warranty, express or implied, or assumes any legal liability or responsibility for the accuracy, completeness, or usefulness of any information, apparatus, product, or process disclosed, or represents that its use would not infringe privately owned rights. Reference herein to any specific commercial product, process, or service by trade name, trademark, manufacturer, or otherwise does not necessarily constitute or imply its endorsement, recommendation, or favoring by the United States Government or any agency thereof. The views and opinions of authors expressed herein do not necessarily state or reflect those of the United States Government or any agency thereof. 


\section{DISCLAIMER}

Portions of this document may be illegible in electronic image products. Images are produced from the best available original document. 
Issued by Sandia Laboratories, operated for the United States Energy Research \& Development Administration by Sandia Corporation.

\section{NOTICE}

This report was prepared as an account of work sponsored by the United States Government. Neither the United States nor the United States Energy Research \& Development Administration, nor any of their employees, nor any of their contractors, subcontractors, or their employees, makes any warranty, express or implied, or assumes any legal liability or responsibility for the accuracy, completeness or usefulness of any information, apparatus, product or process disclosed, or represents that its use would not infringe privately owned rights.

Printed in the United States of America

Available from

National Technical Information Service

U. S. Department of Commerce

5285 Port Royal Road

Springfield, VA 22161

Price: Printed Copy $\$ 3.50$; Microfiche $\$ 3.00$ 


\section{PAGES 1 to 2 WERE INTENTIONALLY LEFT BLANK}


SAND77-0399

Unlimited Release

Printed June 1977

\title{
CHARACTERISTICS OF HOLOGRAMS RECORDED ON AGFA 10E75 PLATES AND PROCESSED IN D6X DEVELOPER

Gary S. Phipps

Clarence E. Robertson

Photometrics Division 9412

Sandia Laboratories

Albuquerque, NM 87115

\begin{abstract}
This study evaluates the results obtained using a new developer (D6X) to produce certain types of holograms on Agfa-Gevaert $10 E 75$ plates. D6X developer when used to produce a gamma of one on $10 E 75$ plates, can produce amplitude holograms with 65 percent of the diffraction efficiency $(\eta)$ of D-19 with a superior signal-to-noise ratio (S/N). The D6X amplitude holograms are comparable in $\eta$ and $S / N$ to $D-19$ plates recorded with higher reference-to-object beam ratios; 1.3 percent efficiency with an $\mathrm{S} / \mathrm{N}$ of 80 was obtained. The D6X processed plates need only onehalf the exposure energy required of D-19 for amplitude holograms, but the exposure latitude is 30 percent larger. For holograms bleached in cupric bromide, the D6X produced lower $\eta$ but had a greatly superior S/N compared to normal bleached D"10 plates. The effect of D6X was comparable to hardening the emulsion in Kodak SH- 5 before development in D-19. Bleached efficiences of 7.4 percent with an $\mathrm{S} / \mathrm{N}$ of 70 were obtained. D6X can produce bleached holograms with $\eta^{23} \%$ and an $S / N \geq 70$ over an exposure range of two orders of magnitude.
\end{abstract}




\section{ILLUSTRATIONS}

\section{Figures}

1. Sensitometric curves of unbleached Agfa-Gevaert 10E75 plates of lot No. 574918.

2. Diffraction efficiency of the virtual image for various reference-to-object beam ratios and two different developers both before and after bleaching in cupric bromide.

3. Diffraction efficiency of the virtual image for a reference-to-object beam ratio of 9 using D6X and Kodak D-19 developers.

4. Signal-to-noise ratio of the virtual image for various reference-to-object beam ratios and two different developers before bleaching.

5. Signal-to-noise ratio of the virtual image for various reference-to-object beam ratios and two different developers after bleaching in cupric bromide. 
CHARACTERISTICS OF HOLOGRAMS RECORDED ON AGFA

1OE75 PLATES AND PROCESSED IN D6X DEVELOPER

Introduction

In order to produce Fourier transform filters with a gamma near 1.0, a low contrast developer designated as D6X was formulated. ${ }^{1}$ Preliminary data indicated that holograms made on Agfa-Gevaert Scientia 10E75 glass holographic plates and processed in D6X to a gamma near 1.0 had diffraction efficiencies approximately 60 percent of the efficiency that would have been obtained had the same plates been processed in Kodak D-19 developer.

The fact that a low contrast (gamma 1.0) process could produce holograms with nearly two-thirds of the diffraction efficiency of a high contrast (gamma $\sim 6.0$ ) process was unexpected. The work reported here is a more thorough investigation of $10 \mathrm{E} 75$ plates used with D6X to make amplitude as well as phase type holograms. The phase type holograms were obtained by bleaching the amplitude holograms in a solution of cupric bromide.

Experimental Results.

The recording setup and measurement techniques used were identical to those used in other studies of $10 \mathrm{E} 75$ plates processed in $\mathrm{D}-19 .{ }^{2,3}$ Briefly, a hologram of a diffusely illuminated 1951 Air Force resolution chart placed 160-mm from the hologram plate was recorded using a 100-mm diameter collimated reference beam, 16 degrees off axis. A single frequency TEMoo He-Ne gas laser was used for the light source. Diffraction efficiency, $\eta$, and gignal-to-noise ratio, $\mathrm{S} / \mathrm{N}$, were measured for the virtual image reconstructed at the center of the hologram by a $10-\mathrm{mm}$ diameter reference beam. $\mathrm{S} / \mathrm{N}$ was measured in the $10 \mathrm{X}$ magnified virtual image, while $\eta$ was measured as the fraction of incident energy diffracted to the virtual image directly behind the plate.

Attention should be called first to the D-Log E data illustrated in Figure 1. The processing sequence used is shuwa velúw.

$\begin{array}{lr}\text { Development }\left(20^{\circ} \mathrm{C}\right) & 5 \text { minutes } \\ \text { Kodak Stop Bath } & 30 \text { seconds } \\ \text { Kodak Rapid Fixer } & 4 \text { minutes } \\ \text { Water Wash } & \cdot \quad 10 \text { minutes } \\ \text { Kodak Photo-Flo } & 30 \text { seconds }\end{array}$

Dry at room temperature 
Not only does the 5-minute D6X process produce a much lower contrast, but it increases the toe speed compared to that of D-19. A density of 0.7 with $\mathrm{D} 6 \mathrm{X}$ for 5 minutes requires an exposure of only $21 \mathrm{ergs} / \mathrm{cm}^{2}$, while for similar $D-19$ processing $32 \mathrm{ergs} / \mathrm{cm}^{2}$ is needed. Less total energy is required, and the lower gamma makes precisely accurate exposure energies less important.

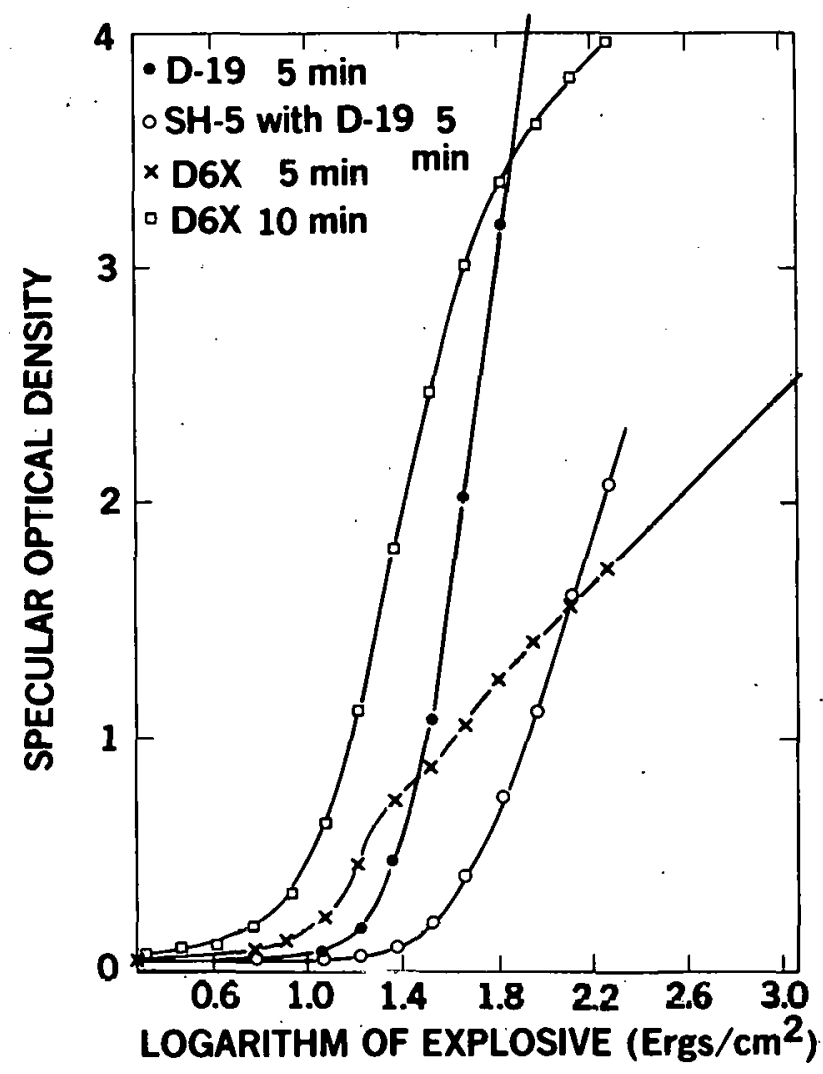

Figure 1. Sensitometric curves of unbleached Agfa-Gevaert 10E75 plates of lot No. 574918. Exposure was with a Macbeth Quantalog Sensitometer using a $10 \AA$ bardpass $6320 \AA$ filter. Density measurements were with a spectral-diffuse Macbeth Quantalog Densitometer. Both D-19 and D6X developer data are given.

If a 3-minute Kodak SH-5 Hardener bath is used to treat the plates before development, it is seen that the sensitivity is reduced by at least a faclur of lwo.

After the plates were developed they were dried before $\eta$ and $\mathrm{S} / \mathrm{N}$ were measured. After measurement, the plates were bleached with cupric bromide in the manner described by Lehmann, ${ }^{4}$ et. al. , with the exception that no prehardener was used. Warller wurk ${ }^{3}$ lidu determined this technique to be desirable for $10 \mathrm{E} 75$ plates processed in $\mathrm{D}-19$. No data were available to indicate that this, bleach would be optimun for D6X; but direct comparisons of $\eta$ and $\mathrm{S} / \mathrm{N}$ to the bleached $\mathrm{D}-19$ data would be possible. 
Figure 2 shows the diffraction efficiency data for both D-19 and D6X before and after bleaching. Three different reference-to-object beam ratios, $K$, were used. For $K=1$, the unbleached D-19 curve peaks at 2.0 percent near an optical density of 0.75 (OD 0.75). The corresponding $\mathrm{D} 6 \mathrm{X}(\mathrm{K}=1)$ curve peaks at 1.3 percent, nearer to OD 0.50 . This confirms that D6X can produce amplitude hologram efficiencies nearly two-thirds (actually 65 percent) of that obtained with D-19. At this lower density level (0.5 vs 0.75$)$. D6X requires only one-half the exposure energy used for an optimum D-19 developed amplitude hologram (see Figure 1). D-19 $(K=4)$ data were included because the $D-19$ maximum amplitude diffraction efficiency is nearly equal to that of $D 6 X(K=1)$. D-19 $(K=1)$ produced the highest $\eta$ in the unbleached state, but after bleaching its value of 15 percent falls slightly below the 16 percent of bleached $\mathrm{D}-19(\mathrm{~K}=4)$. The bleached $\eta$ of $\mathrm{D} 6 \mathrm{X}(\mathrm{K}=1)$ falls considerably below that of $D-19(K=4)$ for all densities above OD 0.9 , but efficiencies of nearly 10 percent can be achieved above OD 1.5; A second $D 6 X$ with $K=9$ was included because it was anticipated that $\mathrm{D} 6 \mathrm{X}(\mathrm{K}=1)$ would not give satisfactory bleached $\mathrm{S} / \mathrm{N}$ values. This $\mathrm{D} 6 \mathrm{X}(\mathrm{K}=9)$ does not extend tö lów enough densities to determine a peak unbleached $\eta$ because only its bleached results were of interest.

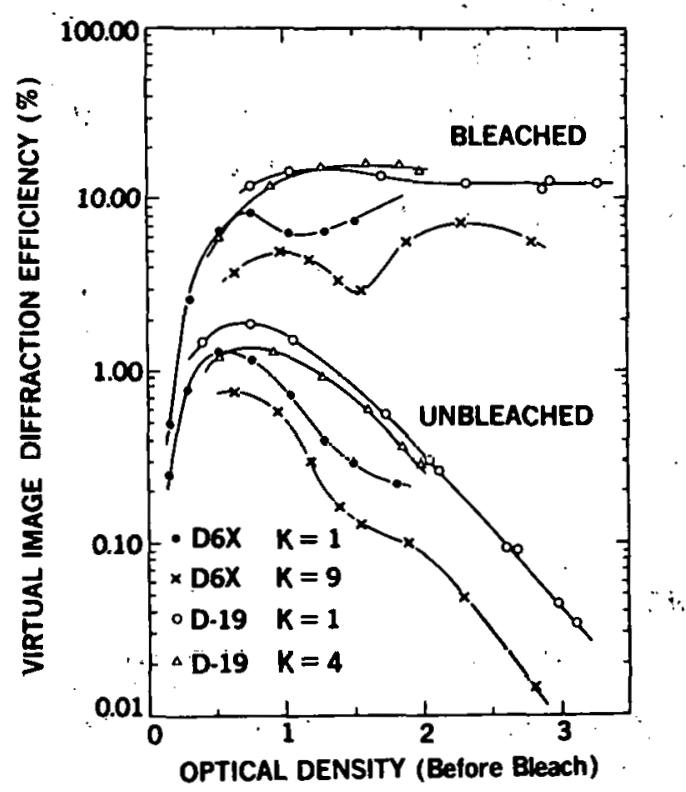

Figure $\dot{2}$.

Diffraction efficiency of the virtual image for various reference-to-object beam ratios and two different developers both before and after bleaching in cupric bromide.

The complete bleach procedure contained in Reference 4 includes a prehardening step in Kodak Hardener SH-5 before development. This increases the $\mathrm{S} / \mathrm{N}$ at the expense of $\eta$ for both the bleached and unbleached cases. The disadvantage is that the speed of the emulsion is decreased in proportion to the length of time it remains in the prehardening bath. Three minutes . were found to be an optimum prehardening time for bleached holograms. Figure 3 is the $\eta$ vs OD data for three series of $K=9$ plates. One series was processed in $D 6 X$, one in straight $D-19$, and the third was soaked for 3 minutes in SH-5 before D-19 development. The $\eta$ curves of $\mathrm{D} 6 \mathrm{X}$ and the prehardened D-19 are roughly similar, falling below a D-19 $(K=9)$ whether or not the plates are bleached. The difference is that $\mathrm{D} 6 \mathrm{X}$ is more sensitive than normal $\mathrm{D}-19$ below $\mathrm{OD} 0.8$, while prehardened D-19 is always a factor of two slower (see Figure 1). 
Figure 3.

Diffraction efficiency of the virtual image for D6X and Kodak D-19 developers. a reference-to-object beam ratio of 9 using

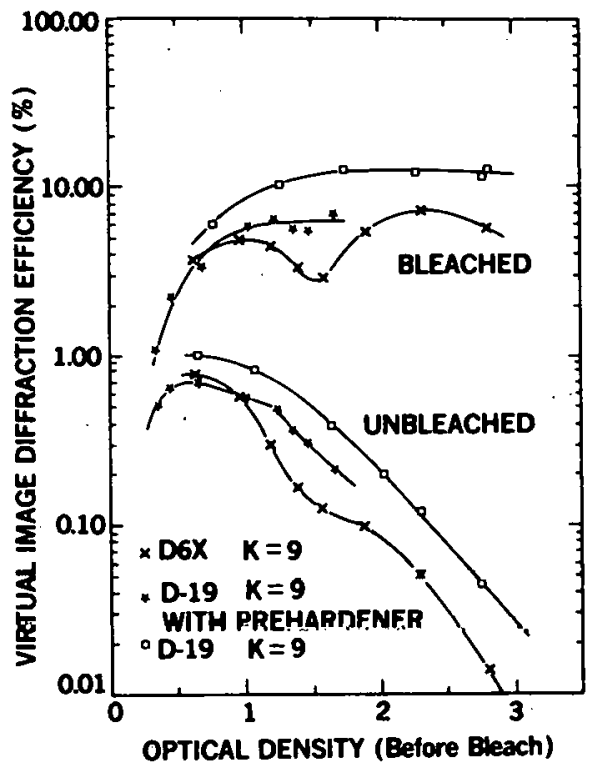

First let us consider the S/N of only unbleached holograms. Figure 4 is the before-bleach $\mathrm{S} / \mathrm{N}$ corresponding to the $\eta$ curves of Figures 2 and 3 . The $\mathrm{S} / \mathrm{N}$ at the $\eta$ peak of $\mathrm{D} 6 \mathrm{X}(\mathrm{K}=1)$ is 80 at $O D$ 0.5, while the nearly equivalent $\eta$ peak of $D-19(K=4)$ at $O D 0.75$ produces a $S / N=90$. It should be noted that at the peak $\eta$ of a $D-19(K=1)$ curve at $O D 0.75$, the $S / N$ value is only slightly over 20. When the beam ratio is increased to $K=9$, the three different development techniques produce an $\mathrm{S} / \mathrm{N}$ at peak $\eta$ which vary somewhat, but all are approaching 200 .

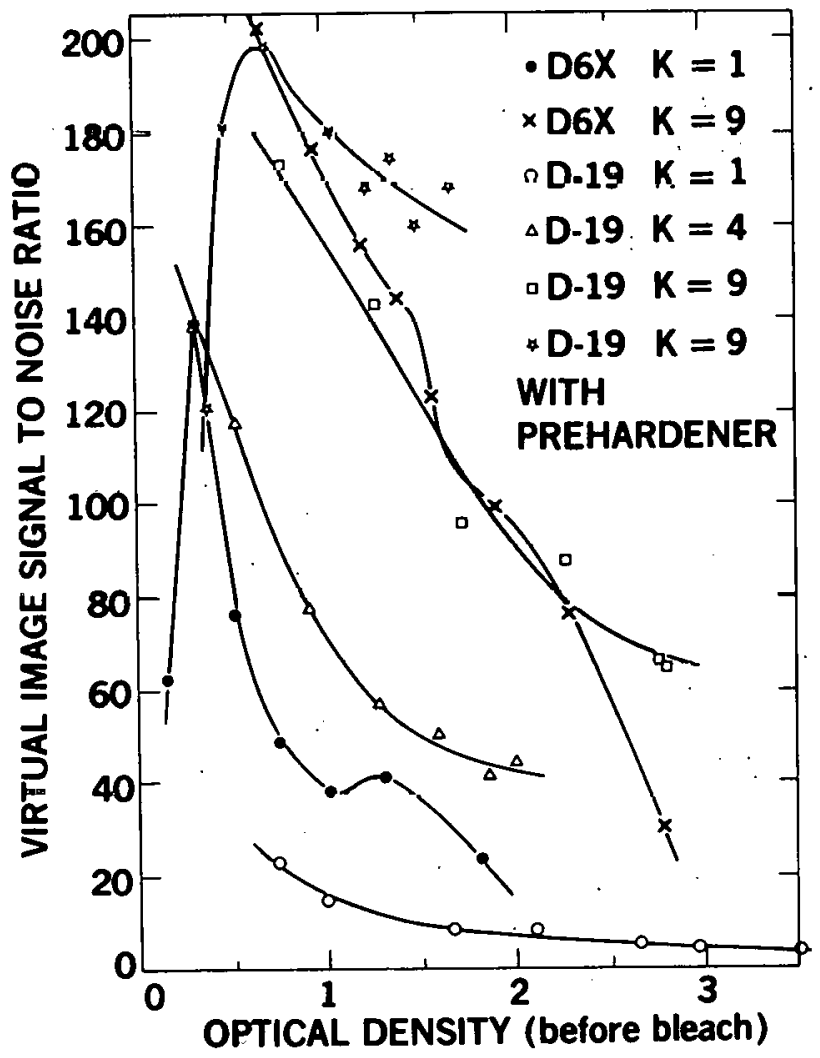

Figure 4.

Signal-to-noise ratio of the virtual image for various reference-to-object beam ratios and two different developers before bleaching. 
Figure 5 is identical to Figure 4 except the data were taken after the plates were bleached in cupric bromide. The D-19 curves reach an $\eta$ peak somewhere in the range of OD 1.5 to 2.0, while the $\mathrm{S} / \mathrm{N}$ monotonically decreases with increasing density. To make use of the higher $\mathrm{S} / \mathrm{N}$, the discussion of bleached D-19 below will assume a before-bleach density of OD 1.5. The D6X does not produce such smooth curves. The discussion below will always mention the D6X beforebleach density being considered for each case.

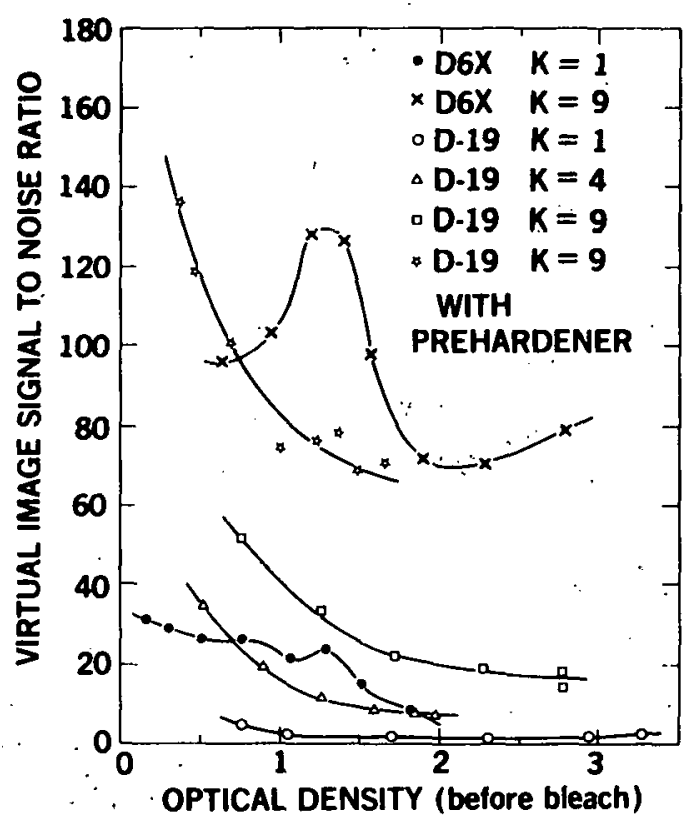

Figure 5.

Signal-to-noise ratio of the virtual image for various reference-to-object beam ratios and two different developers after bleaching in cupric bromide.

The $S / N$ of 10 with $\eta$ of 16 percent for the bleached $(K=4) \mathrm{D}-19$ is low but not nearly as low as the $S / N=2$ with $\eta$ of 15 percent for bleached $D-19(K=1)$. By comparison, the bleached D6X $(\mathrm{K}=1)$ produces an $\mathrm{S} / \mathrm{N}$ of 25 near its first efficiency peak at $\mathrm{OD} 0.9$, corresponding to an $\eta$ of 8 percent. Although the $\mathrm{S} / \mathrm{N}$ of the D6X holograms is higher, the $\eta$ is lower. There seems to be no combination of factors to produce an amplitude $\mathrm{D} 6 \mathrm{X}(\mathrm{K}=1)$ hologram with both $\eta$ and $\mathrm{S} / \mathrm{N}$ préferable to that of $\mathrm{D}-19(\mathrm{~K}-4)$.

At $K=9$, the bleached $D-19$ produces 12 percent efficiency with an $\mathrm{S} / \mathrm{N}$ of 26 . Simply prehardening the emulsion before D-19 development results in only 6 percent efficiency but with an $\mathrm{S} / \mathrm{N}$ of 70. The D6X curve has two peaks, one near OD 1.0 and the other near OD 2.3. At OD 1.0, $\mathrm{D} 6 \mathrm{X}(\mathrm{K}=9)$ gives an $\eta$ of 5 percent with $\mathrm{S} / \mathrm{N}=105$, while at $\mathrm{OD} 2.3$ the $\eta$ increases to 7.4 percent with $\mathrm{S} / \mathrm{N}$ of 70 . Before bleaching, these three methods gave comparable S/Ns. After bleaching, the D6X and prehardened D-19 have greatly superior S/N ratios when compared to the nonhardened $\mathrm{D}-19$. The interesting point is that the bleached $\mathrm{S} / \mathrm{N}$ of the $\mathrm{D} 6 \mathrm{X}$ is not a sharply decreasing function of density. Bleached holograms with exceptionally good S/Ns (in excess of 70) can be made from D6X plates with densities of any value between OD 0.7 and OD 2.7. 
In addition to the $S / N$ and sensitivity advantages, the D6X process is a low contrast process which gives a larger exposure latitude. A nonhardened $D-19(K=4)$ amplitude hologram with $\eta \geq 1 \%$ has a density in the range of OD 0.4 to 1.25 . These densities correspond to an exposure energy range of 1.6X. A similar amplitude D6X hologram would fall in the range of OD 0.35 to 0.85. Even though the permissible density range is smaller than $D-19$, the exposure energy range of 2.1 is 30 percent larger. Similar arguments can be made for bleached D6X holograms. Bleached D6X holograms with $\eta \geq 3 \%$ and $S / N \geq 70$ can be produced with densities anywhere in the range of OD 0.7 to 2.7 , corresponding to an exposure latitude of nearly two orders of magnitude.

\section{Conclusions}

D6X can be used to process $10 \mathrm{E} 75$ hologram plates. The maximum amplitude hologram efficiency is near 1, 3 percent for a complex object, while a similarly recorded hologram processed in D-19 will deliver 2.0 percent. Although efficiency is down, the signal-to-noise ratio is markedly better. The $\eta$ and $S / N$ of a $D 6 X(K=1)$ unbleached plate is nearly identical to that of a $\mathrm{D}-19(\mathrm{~K}=4)$ plate.

If the plates are to be bleached to make phase type holograms, the result of using D6X was found to be roughly equivalent to prehardening the emulsion with Kodak SH- 5 before development in D-19. The resultant plates exhibited reduced efficiency but greatly enhanced $\mathrm{S} / \mathrm{N}$ compared to a normal D-19 bleached hologram. The important difference is that a D6X processed plate is more sensitive than one done in D-19 for densities below 0,8 , while a prehardened D-19 is a factor of 2 less sensitive than a standard D-19.

The large exposure latitude affurded by lie low eontraot of D6Y makes prerise rnntrnl of laser exposure energy less critical. Good amplitude holograms can be produced over an energy range of 2.1X. If bleaching is necessary, even larger exposure latitudes are possible. Depending upon the parameters of importance, an exposure latitude of two orders of magnitude is possible with bleached D6X holograms. 
1. C. E. Robertson, A Low Contrast Long Latitude Developer for High Resolution Plates and Films, Sandia Laboratories, Albuquerque, N. M., SLA-74-0097, June 1974.

2. M. J. Landry and G. S. Phipps, Measurement of Diffraction Efficiency, Resolution and Signal-to-Noise Ratio for Single Exposure and Multiple Exposure Holograms, Sandia Laboratories, Albuquerque, N. M., SAND74-0155, April 1975.

3. G. S. Phipps, M. J. Landry, and C. E. Robertson, Evaluation of Various Bleaching Processes for Single Exposure and Multiple Exposure Holograms, Sandia Labóratories, Albuquerque, N. M., SAND77-0252, April 1977.

4. M. Lehmann, J. P. Lauer, and J. W. Goodman, High Efficiencies, Low Noise, and Suppression of Photochromic Effects in Bleached Silver Halide Holography, App. Opt. 9, p 1948, August 1970 . 


\section{APPENDIX}

The chemical composition of $\mathrm{D} 6 \mathrm{X}$ is given below. Dissolve each chemical in the order given in $500 \mathrm{ml}$ of water.

$\begin{array}{ll}2 \mathrm{gr} & \text { 1-phenyl-3-pyrazolidone } \\ 3 \mathrm{gr} & \text { P-methylaminophenol sulfate } \\ 5 \mathrm{gr} & \mathrm{Na}_{2} \mathrm{CO}_{3} \\ 30 \mathrm{gr} & \mathrm{Na}_{2} \mathrm{SO}_{3}\end{array}$

ndd additinnal water to make 1.0 liter 


\section{DISTRIBUTION:}

2500 J. C. King

2541 G. W. Gobeli

2541 K. T. Stalker

2542 K. R. Hessel

2542 M. J. Landry

5167 J. R. Asay

5242 L. P. Mix

9352 B. D. Hansche

9400 H. E. Lenander

9410 R. L. Brin

9412 R. K. Petersen

9412 G. S. Phipps (10)

9412 C. E. Robertson (10)

8266 E. A. Aas

3141 C. A. Pepmueller (Actg) (5)

3151 W. L. Garner (3) For ERDA/TIC (Unlimited Release)

ERDA/TIC (25)

(R. P. Campbell, 3172-3) 